\title{
Employment grade differences in cause specific mortality. A 25 year follow up of civil servants from the first Whitehall study
}

Caroline T M van Rossum, Martin J Shipley, Hendrike van de Mheen, Diederick E Grobbee, Michael G Marmot

\begin{abstract}
Study objective-To test the hypothesis that the association between socioeconomic status and mortality rates cuts across the major causes of death for middle aged and elderly men.

Design-25 year follow up of mortality in relation to employment grade.

Setting-The first Whitehall study.

Participants-18 001 male civil servants aged 40-69 years who attended the initial screening between 1967 and 1970 and were followed up for at least 25 years.

Main outcome measure-Specific causes of death.

Results-After more than 25 years of follow up of civil servants, aged 40-69 years at entry to the study, employment grade differences still exist in total mortality and for nearly all specific causes of death. Main risk factors (cholesterol, smoking, systolic blood pressure, glucose intolerance and diabetes) could only explain one third of this gradient. Comparing the older retired group with the younger pre-retirement group, the differentials in mortality remained but were less pronounced. The largest decline was seen for chronic bronchitis, gastrointestinal diseases and genitourinary diseases.

Conclusions-Differentials in mortality persist at older ages for almost all causes of death.

(F Epidemiol Community Health 2000;54:178-184)
\end{abstract}

An association between socioeconomic status and mortality has been shown in several studies and countries. ${ }^{1-5}$ Marmot et al suggested that there was a general susceptibility to specific causes of death, as after a 10 year follow up of British civil servants in the first Whitehall study an inverse gradient by employment grade was seen for most causes of death. ${ }^{6}$ However, the number of events used in this analysis was relatively small. After 25 years of follow up of this study population, it is possible to examine these associations again with many more events. Furthermore, it was possible to examine the diversity in the gradients by causes of death and to examine even more specific causes of death.

In previous analyses, employment grade differences have been partly explained by the biological and behavioural factors of smoking, blood pressure and cholesterol. ${ }^{25} 7$ The impact of these risk factors on these employment grade differences in mortality rates were also investigated.

In addition, we might expect the socioeconomic differences in mortality to be less pronounced in old age, as the eventual probability of death for each person reaches $100 \%$. However, social class differentials in mortality are still found in these age groups. ${ }^{8-11}$ A previous analysis of the 25 year follow up data from the first Whitehall study has shown that relative differences in mortality between socioeconomic groups decrease but still persist beyond retirement age and in absolute terms even increase with old age. ${ }^{12}$ The question arises whether this applies to different causes of death to the same extent or whether there are some causes where the grade effects disappear after retirement age. Therefore, we have examined whether the employment grade effects decreased with more years of follow up and whether these associations differ between middle aged men and older retired men.

\section{Methods}

A total of 19019 civil servants aged 40-69 years attended the initial screening of the Whitehall study between September 1967 and January 1970. In short, each participant filled in a standard questionnaire that included age, self reported smoking habit, civil servants' employment grade, and health status. Measurements at the screening examination included blood pressure, plasma cholesterol concentration and a glucose tolerance test. Subjects with a blood glucose, two hours after a post-fasting $50 \mathrm{~g}$ glucose load, above $11.1 \mathrm{mmol} / 1$ or with previously diagnosed diabetes constituted the diabetic group; non-diabetic subjects with glucose concentrations above the 95th centile point (5.4$11.0 \mathrm{mmol} / \mathrm{l}$ ) formed the group with impaired glucose tolerance, and other subjects were designated as being normoglycaemic. Smoking has been categorised according to cigarette use as current smokers, ex-smoker and never smoker. More details regarding design and methods are described elsewhere. ${ }^{13}$ Employment grade was categorised as administrative, professional and executive, clerical, and "other" grades (for example, messengers and other unskilled manual workers). For 886 men from the Diplomatic Service and the British Council, employment grade was not comparable with the grades above and these men have been excluded from the analyses.

Records from $99.3 \%$ of the remaining men were flagged at the National Health Service 
Central Registry, which notified us of all deaths up to the end of January 1995. Causes were classified according to the International Classification of Disease, eighth revision (ICD-8). A total of 18001 men were followed up for at least 25 years and contributed a total of 385660 person years with 8053 deaths. For another 21 subjects the cause of death was missing, these have been excluded from the cause specific mortality analysis.

DATA ANALYSIS

Mortality rates have been calculated using person years at risk. These rates have been standardised for age at entry by the direct method, using five year age bands and with the total population as the standard. The mortality gradients across the four employment grades are close to linear. Therefore, to compare the trends across the employment grade levels between several causes of death we estimated the rate ratio between the lowest and the highest employment grade using Cox's proportional hazards models in which employment grade was added as a continuous variable (values $1,2,3$, and 4 ). We estimated the rate ratio between the highest (that is, administrative) and the lowest employment grade (that is, "others") by taking the exponent of three times the coefficient for employment grade. This method has the advantage of giving a more stable estimate as all the data, rather just the data from the relatively small groups of the "other" grade and administrative grade, are used.

To examine the impact of risk factors on these employment grade differences, mortality rate ratios among subjects who are not currently smoking and who have a low plasma cholesterol level (below the median of 5.0 $\mathrm{mmol} / \mathrm{l}$ ) and a low systolic blood pressure (below $133 \mathrm{~mm} \mathrm{Hg}$ ) were estimated. In addition, the mortality rate ratios based on the whole population were adjusted for several risk factors: smoking, systolic blood pressure, glucose intolerance and diabetes, and cholesterol.

To compare the employment grade differences for three different intervals of follow up $(0-9,10-19,20+$ years $)$, we split our dataset into three parts and computed age adjusted rate ratios for the four employment grades taking the professional/executive as the reference group as the administrative grade had relatively small numbers.

For the analysis of the age specific mortality differentials we also created a new expanded dataset in which for each individual year of follow up a new record was created, consisting of each man's current age at risk together with his employment grade and length of follow up in that year. Deaths were allocated to the appropriate current age category. This dataset

Table 1 Age adjusted mortality rates per 1000 person years (number of deaths) by employment grade and mortality rate ratios for "other" grade versus administrative*

\begin{tabular}{|c|c|c|c|c|c|}
\hline \multirow[b]{2}{*}{ Causes of death (ICD-8) } & \multicolumn{4}{|c|}{ Mortality rates (number of deaths) } & \multirow{2}{*}{$\begin{array}{l}\text { Mortality rate ratio } \\
\text { ( } 95 \% \text { CI) "Other" } \\
\text { grade versus } \\
\text { Administrative* }\end{array}$} \\
\hline & $\begin{array}{l}\text { Administrative } \\
(n=962)\end{array}$ & $\begin{array}{l}\text { Professional/ executive } \\
(n=12 \text { 269) }\end{array}$ & $\begin{array}{l}\text { Clerical } \\
(n=2981)\end{array}$ & $\begin{array}{l}\text { Other } \\
(n=1789)\end{array}$ & \\
\hline All causes & $16.76(295)$ & $20.74(4733)$ & $27.43(1779)$ & $30.91(1246)$ & $2.07(1.90,2.25)$ \\
\hline Malignant neoplasm of lung (162.1) & $0.76(16)$ & $1.53(358)$ & $2.80(181)$ & $3.28(147)$ & $4.08(3.10,5.38)$ \\
\hline Other neoplasms (140-239 excl. 162.1) & $4.00(72)$ & $4.57(1088)$ & $4.94(313)$ & $5.53(207)$ & $1.43(1.17,1.74)$ \\
\hline Ischaemic heart disease $(410-414)$ & $6.41(105)$ & $7.29(1679)$ & $9.10(583)$ & $10.07(394)$ & $1.77(1.53,2.06)$ \\
\hline Cerebrovascular disease $(430-438)$ & $1.43(26)$ & $1.79(380)$ & $2.12(144)$ & $1.81(81)$ & $1.35(0.99,1.85)$ \\
\hline Other cardiovascular $(390-404,420-429,440-458)$ & $1.18(23)$ & $1.73(385)$ & $2.42(160)$ & $2.38(104)$ & $2.13(1.59,2.86)$ \\
\hline Chronic bronchitis (491-492) & $0.10(2)$ & $0.23(44)$ & $0.77(51)$ & $1.14(48)$ & $10.76(5.96,19.42)$ \\
\hline Other respiratory disease $(460-490,493-519)$ & $1.10(20)$ & $1.59(337)$ & $2.82(192)$ & $3.68(155)$ & $4.13(3.15,5.43)$ \\
\hline Gastrointestinal disease $(520-577)$ & $0.66(8)$ & $0.41(94)$ & $0.54(37)$ & $0.88(30)$ & $2.42(1.35,4.36)$ \\
\hline Genitourinary disease (580-607) & $0.25(4)$ & $0.26(53)$ & $0.31(20)$ & $0.51(25)$ & $3.27(1.59,6.71)$ \\
\hline Accident and violence $(800-949,960-978)$ & $0.13(3)$ & $0.20(51)$ & $0.28(16)$ & $0.36(11)$ & $2.38(0.98,5.78)$ \\
\hline Suicide $(950-958,980-989)$ & $0.10(2)$ & $0.17(45)$ & $0.25(15)$ & $0.21(6)$ & $1.65(0.60,4.50)$ \\
\hline Other deaths & $0.57(11)$ & $0.93(207)$ & $1.05(63)$ & $0.97(36)$ & $1.43(0.91,2.24)$ \\
\hline \multicolumn{6}{|l|}{ Causes not related to smoking $\dagger$} \\
\hline Neoplasms & $2.74(53)$ & $2.92(690)$ & $3.12(194)$ & $3.16(114)$ & $1.19(0.92,1.54)$ \\
\hline Non-neoplasms & $5.54(100)$ & $7.12(1564)$ & $9.83(651)$ & $10.91(450)$ & $2.25(1.95,2.60)$ \\
\hline
\end{tabular}

*Based on exponent of three times the coefficient of employment grade assessed with Cox proportional hazards models in which employment grade was added as a continuous variable (values $1,2,3,4)$. tAll causes less 140-141, 143, 149, 150, 157, 160-163, 188-189, 200, 202, 410-414, 491, 492.

Table 2 Age adjusted mortality rates per 1000 person years (number of deaths) by employment grade and mortality rate ratios for "other" grade versus administrative for diseases of the circulatory system

\begin{tabular}{|c|c|c|c|c|c|}
\hline \multirow[b]{2}{*}{ Causes of death (ICD-8) } & \multicolumn{4}{|c|}{ Mortality rates (number of deaths) } & \multirow{2}{*}{$\begin{array}{l}\text { Mortality rate ratic } \\
\text { - } 95 \% \text { CI) "Other" } \\
\text { grade versus } \\
\text { Administrative }\end{array}$} \\
\hline & $\begin{array}{l}\text { Administrative } \\
(n=962)\end{array}$ & $\begin{array}{l}\text { Professional/ executive } \\
(n=12 \text { 269) }\end{array}$ & $\begin{array}{l}\text { Clerical } \\
(n=2981)\end{array}$ & $\begin{array}{l}\text { Other } \\
(n=1789)\end{array}$ & \\
\hline Ischaemic heart disease $(410-414)$ & $6.41(105)$ & $7.29(1676)$ & $9.10(583)$ & $10.07(394)$ & $1.77(1.53,2.06)$ \\
\hline Acute myocardial infarction (410) & $4.15(66)$ & $5.07(1177)$ & $6.27(398)$ & $7.48(286)$ & $1.85(1.55,2.20)$ \\
\hline Chronic ischaemic heart disease (412) & $2.18(37)$ & $2.14(486)$ & $2.70(177)$ & $2.44(103)$ & $1.59(1.21,2.11)$ \\
\hline Cerebrovascular disease $(430-438)$ & $1.43(26)$ & $1.79(380)$ & $2.12(144)$ & $1.81(81)$ & $1.35(0.99,1.85)$ \\
\hline Other cardiovascular $(390-404,420-429,440-458)$ & $1.18(23)$ & $1.73(385)$ & $2.42(160)$ & $2.38(104)$ & $2.13(1.59,2.86)$ \\
\hline $\begin{array}{l}\text { Active rheumatic fever and chronic rheumatic heart } \\
\text { disease }(390-399)\end{array}$ & $0.11(3)$ & $0.16(34)$ & $0.25(15)$ & $0.24(11)$ & $2.65(1.03,6.84)$ \\
\hline Hypertensive disease (400-404) & $0.06(1)$ & $0.15(36)$ & $0.19(12)$ & $0.20(10)$ & $2.44(0.92,6.51)$ \\
\hline Other forms of heart disease $(420-429)$ & $0.25(5)$ & $0.46(100)$ & $0.70(46)$ & $0.60(28)$ & $2.13(1.21,3.74)$ \\
\hline Diseases of arteries, arterioles and capillaries (440-447) & $0.45(8)$ & $0.69(152)$ & $0.92(63)$ & $1.08(43)$ & $2.24(1.41,3.57)$ \\
\hline Aortic aneurysm (441) & $0.24(4)$ & $0.53(118)$ & $0.68(45)$ & $0.86(34)$ & $2.52(1.48,4.30)$ \\
\hline $\begin{array}{l}\text { Diseases of veins and lymphatics and other diseases of } \\
\text { circulatory system }(450-458)\end{array}$ & $0.16(3)$ & 0.40 (37) & $0.22(15)$ & $0.14(7)$ & $1.76(0.64,4.87)$ \\
\hline
\end{tabular}


was split into three parts depending on the subject's current age. As men at lower risk of death had on average, a longer follow up, we adjusted these analyses for the length of follow up and also adjusted for age using five year age groups. All analyses were done using the statistical package SAS. ${ }^{14}$

\section{Results}

Table 1 shows the age adjusted mortality rates by employment grade and the rate ratio of the lowest versus the highest employment grade for all the broad major causes of death after more than 25 years of follow up. The mortality rate was higher for all these major causes of death in the lower grades compared with the higher grades and was statistically significant in almost all cases. The largest differences were found for lung cancer, chronic bronchitis and respiratory diseases. Looking at the differences in absolute rates, cardiovascular diseases and neoplasms contributed the largest part to the differences between the mortality rates by grade.

For some groups of diseases, for example "other neoplasms", the weak association was caused by the heterogeneity between the strength, and, to a lesser extent, direction of the associations for the diseases within the group (test for heterogeneity; $p<0.01$ ). This heterogeneity between specific cancer sites was similar (data not shown) to a previous analyses of Davey Smith et al. ${ }^{15}$ Socioeconomic differentials for subcategories of cardiovascular diseases are reported in table 2 . In contrast with the heterogeneous effects across cancer sites, the socioeconomic differentials in diseases of the circulatory system were quite homogeneous with rate ratios varying between 1.35 and 2.65 .

Table 3 shows the grade differences in mortality for the low risk group. The estimated mortality rate ratio is not given for those causes with fewer than 20 deaths. Even in this low risk group an employment gradient is seen in total mortality. Only 38 of the 702 of the lung cancer deaths occurred in this non-smoking subgroup. For most other specific causes of death the
KEY POINTS

- Social differentials influence most causes of disease and these effects continue through into retirement.

- Main risk factors could only explain one third of the gradient.

- Comparing the older retired persons with the younger pre-retirement persons, employment grade differences in mortality remained but were less pronounced.

- The largest decline with age was seen for chronic bronchitis, gastrointestinal diseases and genitourinary diseases.

employment grade gradients are even steeper in this low risk group compared with those in the whole study population. Furthermore, mortality rate ratios that are adjusted for age and the major risk factors and based on the whole population are shown in table 3. Adjustment for these risk factors reduced the employment grade differences for almost all specific causes of death. About one third of the employment grade differences in total mortality could be explained by these differences in risk factors.

The 25 year follow up gave us the opportunity to examine whether the mortality rate ratios with employment grade were the same after different intervals of follow up. Figure 1 shows the rate ratios for total and cause specific mortality after the first 10 years of follow up, the second 10 years of follow up and for the follow up after 20 years. In general, the differentials in mortality decreased slightly, after more years of follow up. However, the employment grade differences in mortality persisted even after more than 20 years of follow up.

To examine the differentials in mortality, pre- and post-retirement, we calculated the employment grade differences in mortality by three age groups and adjusted for the length of follow up. Table 4 shows the rate ratios for the "other" versus administrative grade by the three age groups. In the older age groups there were a smaller proportion of deaths from

Table 3 Age adjusted mortality rate ratios for "other" grade versus administrative for non-smokers with a low cholesterol and low systolic blood pressure and mortality rate ratios, adjusted for age and risk factors, for the whole population

\begin{tabular}{|c|c|c|c|}
\hline \multirow[b]{2}{*}{ Causes of death (ICD-8) } & \multicolumn{2}{|c|}{$\begin{array}{l}\text { Non-smokers with low plasma cholesterol } \\
\text { and low blood pressure }(n=2376)\end{array}$} & \multirow{2}{*}{$\begin{array}{l}\text { Whole population ( } n=18001) \\
\text { Mortality rate ratio ( } 95 \% \text { CI) } \\
\text { adjusted for age and risk factorst, } \\
\text { "Other" grade versus } \\
\text { Administrative }\end{array}$} \\
\hline & $\begin{array}{l}\text { Number } \\
\text { of deaths }\end{array}$ & $\begin{array}{l}\text { Mortality rate ratio }(95 \% \text { CI) } \\
\text { adjusted for age; "Other" } \\
\text { grade versus Administrative }\end{array}$ & \\
\hline All causes & 614 & $2.30(1.54,3.43)$ & $1.75(1.60,1.91)$ \\
\hline Malignant neoplasm of lung (162.1) & 38 & $0.59(0.12,2.96)$ & $2.75(2.09,3.63)$ \\
\hline Other neoplasm (140-239 excl. 162.1) & 184 & $1.28(0.65,2.50)$ & $1.36(1.11,1.66)$ \\
\hline Ischaemic heart disease $(410-414)$ & 173 & $2.61(1.39,4.89)$ & $1.52(1.24,1.86)$ \\
\hline Cerebrovascular disease $(430-438)$ & 38 & $1.51(0.38,6.03)$ & $1.11(0.81,1.53)$ \\
\hline Other cardiovascular $(390-404,420-429,440-458)$ & 44 & $4.37(1.25,15.28)$ & $1.66(1.23,2.24)$ \\
\hline Chronic bronchitis (491-492) & 9 & $\ddagger$ & $6.53(3.59,11.87)$ \\
\hline Other respiratory disease $(460-490,493-519)$ & 52 & $11.09(3.59,34.39)$ & $2.98(2.26,3.93)$ \\
\hline Gastrointestinal disease $(520-577)$ & 19 & $\neq$ & $1.93(1.07,3.49)$ \\
\hline Genitourinary disease $(580-607)$ & 10 & $\ddagger$ & $2.61(1.25,5.46)$ \\
\hline Accident and violence $(800-949,960-978)$ & 9 & $\ddagger$ & $2.47(1.00,6.10)$ \\
\hline Suicide $(950-958,980-989)$ & 4 & $\ddagger$ & $1.20(0.43,3.37)$ \\
\hline Other deaths & 32 & $3.40(0.78,14.68)$ & $1.24(0.78,1.97)$ \\
\hline
\end{tabular}

*Non-smokers (never and ex-smokers) with cholesterol and systolic blood pressure values below the median; cholesterol $<5.0$; systolic blood pressure <133. †Adjusted for age, smoking, systolic blood pressure, plasma cholesterol concentration and glucose intolerance. $¥$ Mortality rate ratio not estimated for causes of death with less than 20 deaths. 



Administrative

Professional executive

Clerical

Other

Figure 1 Age adjusted mortality rate ratios (with the professionallexecutive grade used as the reference group) by employement grade and three periods of follow up: 0-9 years, 10-19 years and 20-27 years of follow up.

ischaemic heart diseases but this was compensated by greater proportions attributable to cerebrovascular disease, other cardiovascular disease and other respiratory diseases. In all three age groups, a gradient was seen between employment grade and total mortality and most specific causes of death. In general, the associations in the youngest age group were steeper than in the higher age groups. The rate ratios for employment grade in those men aged 65-69 years were not always significant because of the small numbers of deaths. The steepest decrease in gradient with increased age was seen for mortality caused by chronic bronchitis, gastrointestinal disease and genitourinary disease. Most of the decrease in the gradient for these causes was seen between the youngest pre-retirement, age group and the older two age groups.

\section{Discussion}

After more than 25 years of follow up of civil servants, aged 40-69 years at entry to the study, the inverse gradient by employment grade still existed in total mortality and for nearly all specific causes of death. The mortality rates were highest in the lower employment grades. Cardiovascular diseases and cancers contributed most to the absolute differences in the total mortality rates by employment grade although the largest relative differences are found for respiratory diseases (chronic bronchitis, lung cancer). The strength of the associations for the specific cardiovascular causes of death did not vary materially. About one third of the employment grade differences could be explained by the distribution in the major risk factors. Except for lung cancer, differences between employment grades are also found in subjects with a low blood pressure, who are not smoking and have a low plasma cholesterol level. Employment grade differences declined slightly after more years of follow up, but are still present in the survivors after 20 years of follow up. The decline in relative differences in mortality with age was the highest for chronic bronchitis, gastrointestinal disease and genitourinary diseases. However, even in retired subjects, socio- 
Table 4 Mortality rate ratios for "other" grade versus administrative by age at death

\begin{tabular}{|c|c|c|c|c|c|c|}
\hline \multirow[b]{2}{*}{ Causes of death (ICD-8) } & \multicolumn{2}{|c|}{$\begin{array}{l}40-64 \text { years } \\
(221720 \text { person years) }\end{array}$} & \multicolumn{2}{|c|}{$\begin{array}{l}65-69 \text { years } \\
(72166 \text { person years })\end{array}$} & \multicolumn{2}{|c|}{$\begin{array}{l}70 \text { years and older } \\
\text { (91 } 775 \text { person years) }\end{array}$} \\
\hline & $\begin{array}{l}\text { Number of } \\
\text { deaths }\end{array}$ & $\begin{array}{l}\text { Mortality rate ratio* } \\
(95 \% \mathrm{CI})\end{array}$ & $\begin{array}{l}\text { Number of } \\
\text { deaths }\end{array}$ & $\begin{array}{l}\text { Mortality rate ratio* } \\
(95 \% \text { CI })\end{array}$ & $\begin{array}{l}\text { Number of } \\
\text { deaths }\end{array}$ & $\begin{array}{l}\text { Mortality rate ratio * } \\
(95 \% \mathrm{CI})\end{array}$ \\
\hline All causes & 1881 & $2.91(2.42,3.50)$ & 1453 & $2.15(1.75,2.65)$ & 4719 & $1.72(1.54,1.92)$ \\
\hline Malignant neoplasm of lung (162.1) & 193 & $5.35(3.15,9.11)$ & 147 & $3.22(1.75,5.93)$ & 362 & $3.61(2.48,5.26)$ \\
\hline Other neoplasms (140-239) & 415 & $1.76(1.16,2.67)$ & 332 & $1.68(1.07,2.66)$ & 933 & $1.17(0.91,1.52)$ \\
\hline Ischaemic heart disease $(410-414)$ & 779 & $2.57(1.93,3.43)$ & 539 & $1.71(1.22,2.41)$ & 1443 & $1.44(1.18,1.76)$ \\
\hline Cerebrovascular disease $(430-438)$ & 80 & $2.50(1.02,6.11)$ & 95 & $1.16(0.50,2.72)$ & 456 & $1.17(0.81,1.67)$ \\
\hline Other cardiovascular $(390-404,420-429,440-458)$ & 130 & $2.07(1.00,4.30)$ & 106 & $3.04(1.44,6.42)$ & 436 & $1.79(1.26,2.55)$ \\
\hline Chronic bronchitis (491-492) & 34 & $29.77(9.03,98.11)$ & 28 & $8.80(2.28,33.98)$ & 83 & $8.25(3.81,17.86)$ \\
\hline Other respiratory disease $(460-490,493-529)$ & 71 & $4.71(1.89,11.75)$ & 85 & $5.21(2.29,11.82)$ & 548 & $3.66(2.71,4.95)$ \\
\hline Gastrointestinal disease $(520-577)$ & 29 & $10.30(2.74,38.78)$ & 31 & $0.48(0.09,2.54)$ & 109 & $2.24(1.11,4.53)$ \\
\hline Genitourinary disease (580-607) & 16 & $9.44(1.54,57.82)$ & 12 & $2.84(0.33,24.78)$ & 74 & $2.58(1.12,5.94)$ \\
\hline Accident and violence $(800-949,960-978)$ & 38 & $3.94(1.07,14.55)$ & 12 & $11.01(1.37,88.6)$ & 31 & $0.73(0.17,3.11)$ \\
\hline Suicide $(950-958,980-989)$ & 34 & $1.61(0.35,7.32)$ & 14 & $3.98(0.55,28.85)$ & 20 & $0.73(0.12,4.60)$ \\
\hline Other deaths & 52 & $4.09(1.34,12.42)$ & 49 & $3.94(1.23,12.55)$ & 216 & $0.92(0.53,1.57)$ \\
\hline \multicolumn{7}{|l|}{ Causes not related to smoking $\dagger$} \\
\hline Neoplasms & 252 & $1.58(0.92,2.74)$ & 198 & $1.52(0.83,2.76)$ & 601 & $0.92(0.67,1.28)$ \\
\hline Non-neoplasms & 450 & $3.31(2.27,4.81)$ & 404 & $2.65(1.79,3.93)$ & 1890 & $1.89(1.60,2.24)$ \\
\hline
\end{tabular}

*Adjusted for age and length of follow up. †All causes less 140-141, 143, 149, 150, 157, 160-163, 188-189, 200, 202, 410-414, 491, 492.

economic differences were found for almost all causes of death.

Before discussing possible mechanisms behind these differences, some potential artefactual explanations need to be considered. All subjects were, at entry to the study, working in stable, sedentary jobs in one location, so that the civil service employment grade categories produce groups that are more homogeneous, for example, with respect to aspects of material circumstances, than most socioeconomic groups in other similar studies of inequalities. As a consequence, differentials might be expected to be larger than equivalent socioeconomic differences in the British population. ${ }^{15}$

In addition, our findings might be affected by misclassification of the causes of death or employment grade. There is evidence that, in the past, working class patients were more likely to be diagnosed as suffering from other myocardial degeneration while middle class patients were more likely to receive a more specific diagnosis of angina pectoris. However, Samphier reported a study in which they matched the diagnostic agreement about cause of death between clinicians and pathologists. ${ }^{16}$ They concluded that although the diagnostic agreement does indeed vary with social class of the patient, the variation is small and in all the major diagnostic chapters, except respiratory diseases, the effect of correcting such diagnostic biases would either not affect or steepen existing class gradients. Thus, the steep differences for respiratory diseases may partly be a consequence of under diagnosis in the higher employment grades and over diagnosis in the lower employment grades.

Any misclassification of employment grade is not likely to be large. In addition, employment grade as an indicator of socioeconomic status has been shown to be a powerful predictor of mortality and morbidity and generally has shown steeper mortality differentials than national data based on the Registrar General's classification of occupations.

Explanations for the social class inequalities in morbidity and mortality have been sought in health selection or in health related behavioural or material factors that are differently distrib- uted over the employment grades. ${ }^{17}$ Unfortunately, we did not measure morbidity or changes in employment grade. However, our differentials found after 20 years of follow up and results from other studies, suggest that the effect of selective social mobility is limited. ${ }^{18} 19$ Similar to the results after 10 years of follow up, ${ }^{6}$ the main risk factors of smoking, blood pressure, cholesterol and glucose, as measured at the initial examination, explain about one third of the socioeconomic differentials in mortality. The contribution of risk factors to the explanation of the inequalities depends upon the fact that the risk factors were measured only once, at baseline, and so provide probably weaker measures of the true risk factors with increasing length of follow up, as the risk profile may change. However, previous analysis has shown that the predictive value of cholesterol measurements is larger with increasing time gap between measurement and death. ${ }^{20}$ The contribution of risk factors to the explanation of the inequalities depends also upon the strength of the association between these factors and socioeconomic status and also on the diversity of risk factors that can cause the disease. It is interesting to contrast the results for lung cancer and respiratory disease in those men at low risk with the results of the total population in this respect. The attributable risk for smoking on lung cancer is quite high and we do not see socioeconomic differentials for lung cancer in the low risk group. However, the increased employment grade gradient for respiratory disease in the low risk men suggests that, besides smoking, the working and living environment may differ among the employment grades. The underlying risk factors for diseases might also explain the diversity in differentials for cancers compared with the similarity in differentials for cardiovascular diseases. In contrast with cancer, ischaemic cardiovascular disease is a so called "general disease". The process of atherosclerosis occurs in the whole arterial system, thus, most cardiovascular diseases have the same risk factors, while the risk factors for cancers are quite different. 
Apart from the major risk factors of smoking, blood pressure, glucose and cholesterol, other behavioural or material factors might play a part in inequalities. One of these factors is unfavourable working conditions that may be linked either to external harmful exposures such as chemicals, or dust pollution in industrial settings or to stress, or job control more generally. ${ }^{21-23}$ Our study population were office-based civil servants, but despite the relatively homogeneous study population, working circumstances might vary by employment grade. The observed decline in employment grade differences after retirement age for most causes of mortality suggest that working conditions might explain some of these inequalities. For example, it is known that gastrointestinal diseases are associated with occupational stress, ${ }^{24}$ and that chronic bronchitis can be induced by working conditions. ${ }^{25}$ We do, indeed, see large changes in the employment grade gradient for these outcomes after retirement. The effect of some working conditions, which contribute to the differentials in health and mortality, may continue to have influence into the old age. For example, the lag time between some exposures and a disease would pass the retirement age. Similarly, behavioural factors, which may be associated with employment grade, will not change on the day of retirement.

An additional explanation for the socioeconomic differences in mortality has been suggested: employment grade is associated with factors that influence someone's general susceptibility to diseases. ${ }^{5}$ Our results support this assertion, as the main risk factors could not fully explain the employment grade differences in all causes of death. Furthermore, among a low risk group with respect to hypertension, cholesterol and smoking, employment grade differences in mortality were still found. In addition, the results suggest that this general susceptibility continues through into retirement. Despite this, we can conclude that persons with a higher socioeconomic status are consistently better off compared with lower socioeconomic groups. The mechanism behind this needs further research.

The diminishing inequalities with age might be because of the declining influence of work circumstances, but there are other possible explanations. Firstly, the time interval since measurement of employment grade would tend to be longer for the oldest age group and factors other than work that account for mortality gradients would change. This would tend to diminish the effect of grade. Secondly, the decline could be caused by selective mortality. It is likely that selective removal of sick people results in a relatively healthier population. However, other analyses of this cohort have shown that differential mortality attributable to hypertension and hypercholesterolaemia is limited, and the effect attributable to smoking is small. ${ }^{26}$ Thirdly, the larger inequalities in the younger age groups relate to the fact that in the United Kingdom, in recent decades, the inequalities are widening ${ }^{27}$ and thus this suggests that, in the future, among the elderly the inequalities will also widen.

In conclusion, socioeconomic differentials in mortality still persist at older ages for almost all causes of death. The effect of socioeconomic status thus has a long term effect. For some specific causes of death the influence of work on inequalities will decline. Further research looking at changes in risk factors may be helpful in elucidating the aetiology of inequalities. For this reason, the surviving men in this cohort have been re-contacted to obtain updated risk factor information. We conclude that, together with more general socioeconomic factors, working conditions themselves may affect a broad range of health inequalities among middle aged men. In addition, social differentials influence most causes of disease and these effects continue through into retirement.

The Whitehall population is largely "white collar" and misses those not in work. The mortality differentials are, however, in the same direction and of the same order as observed in the general population in Britain and elsewhere. ${ }^{28}$ It is a problem of profound importance. $^{29}$

Funding : this study is a collaboration between the International Centre for Health and Society in London and the research programme of the Erasmus Centre for Research on Ageing, a collaboration of the departments Economics, Law, Sociology, Medicine and Health Policy and Management of the Erasmus University Rotterdam and the University Hospital Rotterdam Dijkzigt, The Netherlands. CTMvR is supported for this project by the Dutch Heart Foundation and the Netherlands Organization for Scientific Research (NWO); MJS is supported by the British Heart Foundation; MGM is a Medical Research Council research professor.

Conflicts of interests: none.

1 Valkonen T. Adult mortality and level of education: a comparison of six countries. In: Fox J, ed. Health inequalities in European countries. Aldershot: Gower, 1989:142-62.

2 Kaplan GA, Keil JE. Socioeconomic factors and cardiovascular disease: a review of the literature. Circulation 1993;88: 1973-98.

3 Mackenbach JP. Socioeconomic inequalities in health in the Netherlands: impact of a five year research programme. BM7 1994;309:1487-91.

4 Mackenbach JP, Kunst AE, Cavelaars AE, et al. Socioeconomic inequalities in morbidity and mortality in western Europe. The EU Working Group on Socioeconomic Inequalities in Health. Lancet 1997;349:1655-9.

5 Marmot MG, Rose G, Shipley M, et al. Employment grade and coronary heart disease in British civil servants. $\mathcal{F}$ Epidemiol Community Health 1978;32:244-9.

6 Marmot MG, Shipley MJ, Rose G. Inequalities in death-specific explanations of a general pattern? Lancet 1984;i:1003-6.

7 Davey Smith G, Shipley MJ, Rose G. Magnitude and causes of socioeconomic differentials in mortality: further evidence from the Whitehall Study. 7 Epidemiol Community Health 1990;44:265-70.

8 Guralnik JM, Land KC, Blazer D, et al. Educational status and active life expectancy among older blacks and whites. N Engl f Med 1993;329:110-16.

9 Kaplan GA, Seeman TE, Cohen RD, et al. Mortality among Kaplan GA, Seeman TE, Cohen RD, et al. Mortality among
the elderly in the Alameda County Study: behavioral and demographic risk factors. Am f Public Health 1987;77:30712 .

10 Martelin T. Mortality by indicators of socioeconomic status among the Finnish elderly. Soc Sci Med 1994;38:1257-78

11 Jefferys $M$. Social inequalities in health-do they diminish with age? Am F Public Health 1996;86:474-5.

2 Marmot MG, Shipley MJ. Do socioeconomic differences in mortality persist after retirement? 25 year follow up of civil servants from the first Whitehall study. BMF 1996;313: 1177-80.

13 Reid DD, Brett GZ, Hamilton PJ, et al. Cardiorespiratory disease and diabetes among middle-aged male Civil Servants. A study of screening and intervention. Lancet 1974;i:469-73.

14 SAS-Institute. SAS user's guide. Carey, NC: SAS Institute Inc, 1985.

15 Davey Smith G, Leon D, Shipley MJ, et al. Socioeconomic differentials in cancer among men. Int f Epidemiol 1991;20: differentials

16 Samphier ML, Robertson C, Bloor MJ. A possible artefactual component in specific cause mortality gradi- 
ents. Social class variations in the clinical accuracy of death certificates. 7 Epidemiol Community Health 1988;42:13843.

17 Blane D. An assessment of the Black report's explanations of health inequalities. Sociology Health Illness 1985;7:423-45. 18 Goldblatt P. Mortality by social class, $1971-85$. Popul Trends 1989;56:6-15.

19 Goldblatt P. Changes in social class between 1971 and 1981: could these affect mortality differential among men of working age? Popul Trends 1988;51:9-17.

20 Shipley MJ, Pocock SJ, Marmot MG. Does plasma cholesterol concentration predict mortality from coronary heart disease in elderly people? 18 year follow up in Whitehall study. BMF 1991;303:89-92.

21 Marmot M, Theorell T. Social class and cardiovascular disease: the contribution of work. Int $\mathcal{f}$ Health Serv 1988;18:659-74.

22 Bosma $\mathrm{H}$, Marmot MG, Hemingway $\mathrm{H}$, et al. Low job control and risk of coronary heart disease in Whitehall II (prospective cohort) study. BMF 1997;314:558-65.
23 Marmot MG, Bosma $\mathrm{H}$, Hemingway $\mathrm{H}$, et al. Contribution of job control and other risk factors to social variations in coronary heart disease incidence. Lancet 1997;350:235-9.

24 Hill P. It is not what you eat, but how you eat it digestion, life-style, nutrition. Nutrition 1991;7:385-95.

25 House JS, Strecher V, Metzner HL, Robbins CA. Occupational stress and health among men and women in the Tecumseh Community Health Study. 7 Health Soc Behav 1986;27:62-77.

26 van de Mheen PJ. Facts and artefacts. Variation in risk factor and the impact on estimated potential health benefits. Amsterdam: University of Amsterdam, 1997.

27 Marmot MG, McDowall ME. Mortality decline and widening social inequalities. Lancet 1986;ii:274-6.

28 Drever FD, Whitehead M. Health Inequalities: Decennial Supplement 1997. Series DS No. 15. London: The Stationery Office, $1-257$.

29 Independent Inquiry. Inequalities in health. London: Stationery Office, 1999. 